\title{
FACTORES QUE AFECTAN EL INTERVALO PARTO-PRIMER SERVICIO Y PRIMER SERVICIO-CONCEPCIÓN EN VACAS LECHERAS DEL VALLE DEL MANTARO DURANTE LA ÉPOCA LLUVIOSA
}

\author{
Carlos Arana D. ${ }^{1}$, Luisa Echevarría C. ${ }^{2}$ y Julia Segura C. ${ }^{3}$
}

\section{AbSTRACT}

A reproductive study was conducted in the El Mantaro valley, Junín, Peru. Forty milking cows from 6 farms were monitored during the rainy season. The effect of breed, parity, milk yield, farm, and technological level on the interval from calving to first ovulation (CFOI), to first service (CFSI), and to conception (CCI) were evaluated. CFOI was determined through progesterone radioimmunoassay concentration in defatted milk. CFOI was within the expected range for dairy cattle ( $41.2 \pm 20.2$ days); however, CFSI (118.4 \pm $69.2)$ and CCI (171.3 \pm 105.5 days) were too long, possibly due to heat detection failures and nutritional constraints. Farm technological level was the only variable of importance that affected CFSI.

Key words: calving to first ovulation interval, calving to first service interval, calving to conception interval

\section{Resumen}

Se realizó un seguimiento reproductivo en 40 vacas lecheras del valle del Mantaro (Junín, Perú), pertenecientes a 6 establos, durante la época lluviosa. Se determinó el intervalo parto-primera ovulación (IPPO), el intervalo parto-primer servicio (IPPS), y el intervalo parto-concepción (IPC), midiendo el efecto de raza, número de parto, producción de leche, establo y nivel tecnológico. El IPPO se determinó a través de niveles de progesterona mediante radioinmunoensayo en muestras de leche descremada. El intervalo observado entre el parto y la primera ovulación (41.2 \pm 20.2 días) estuvo dentro de los rangos esperados para bovinos de producción de leche criados bajo las condiciones del presente estudio. Sin embargo, los intervalos entre el parto al primer servicio (118.4 \pm $69.2)$ y a la concepción (171.3 \pm 105.5 días) fueron muy prolongados, debido posiblemente a problemas en la detección del celo y limitantes nutricionales. El nivel tecnológico de los establos fue la única variable de importancia que afectó el intervalo parto-primer servicio.

Palabras clave: intervalo parto-primera ovulación, intervalo parto-primer servicio, intervalo parto-concepción

${ }^{1}$ Estación Experimental IVITA-El Mantaro, FMV-UNMSM

${ }^{1}$ Laboratorio de Reproducción Animal, FMV-UNMSM. E-mail: luisa ech@hotmail.com

${ }^{2}$ Facultad de Veterinaria y Zootecnia, Universidad Peruana Cayetano Heredia

${ }^{3}$ Práctica privada 


\section{INTRODUCCIÓN}

La demanda de leche y productos lácteos en el valle del Mantaro se ha incrementado en los últimos años. Esto se debe a un aumento en el consumo de leche en la capital, y a la afluencia de turistas en la zona, lo cual condiciona una demanda de leche fresca fluida, pero principalmente de derivados lácteos.

El reinicio de la ciclicidad ovárica postparto se encuentra afectado por la raza, la edad, el número de parto, el estado nutricional, los cambios de peso durante el puerperio, las enfermedades perinatales, el amamantamiento y la producción de leche, entre otros. El inmediato reinicio de la actividad ovárica postparto facilita las posibilidades de que el animal presente un intervalo corto entre el parto y la concepción, y de esa manera, se pueda aumentar el rendimiento de producción de leche durante su vida productiva. En general, las vacas lecheras en crianza intensiva reinician su actividad cíclica alrededor de los 30 días del parto, aunque la manifestación del celo puede pasar desapercibida (Arthur, 1991; Hafez, 1987). El reinicio de la actividad ovárica está regulado por el eje hipotálamohipófisis-gónada, en base a un adecuado balance endocrino y al reestablecimiento de la funcionalidad uterina (Friend, 1991).

En el valle del Mantaro se distinguen tres zonas agro ecológicas importantes: alta, media y baja. En esta última se desarrolla la producción lechera con animales especializados de la raza Brown Swiss y Holstein, principalmente. El presente trabajo se desarrolló en la parte baja del valle y tuvo por objetivo determinar el momento del reinicio de la actividad ovárica y el comportamiento reproductivo postparto durante la época lluviosa.

\section{Materiales y Métodos}

\section{Lugar de estudio}

El estudio se llevó a cabo en el valle del Mantaro, ubicado en la Sierra Central del departamento de Junín, con una altitud media de 3,320 metros sobre el nivel del mar, y con una temperatura y precipitación anual promedios de $12^{\circ} \mathrm{C}$ y $750 \mathrm{~mm}$, respectivamente. Los establos estuvieron ubicados en las provincias de Huancayo, Concepción y Jauja.

\section{Animales}

Se seleccionaron 40 vacas postparto de las razas Holstein y Brown Swiss con edad promedio de 4 años. Se registró la identificación, edad, raza, número de partos, fecha del último parto, producción láctea, fecha del primer servicio y confirmación de preñez. La ubicación y número de animales por establo se indica en el Cuadro 1.

\section{Manejo}

Los establos presentaron un sistema de crianza al pastoreo (pastura cultivada) con suplementación de ensilaje. Las pasturas fueron mayormente asociaciones de gramíneas (rye grass inglés, rye grass italiano, dactylis) y leguminosas (trébol rojo y trébol blanco). Los establos fueron clasificados según nivel tecnológico en "A" (mayor nivel tecnológico, ordeño mecánico, destete temprano [3-15 días]; programa de detección de celos) y "B" (menor nivel tecnológico, ordeño manual, ternero al pie por periodos prolongados $[3$ meses], detección de celos en forma irregular). (Cuadro 1).

\section{Obtención y análisis de muestras}

Se recolectaron muestras de leche dos veces por semana a partir del día 15 postparto, entre los meses de noviembre de 1998 y abril de 1999 (época lluviosa). Las muestras fueron preservadas con azida de sodio, se descremaron por centrifugación (2000 rpm/ $10 \mathrm{~min}$ ) y se conservaron a $-20{ }^{\circ} \mathrm{C}$ hasta su análisis en el Laboratorio de Reproducción Animal de la Facultad de Medicina Veterinaria de la Universidad Nacional Mayor de San Marcos. 
Cuadro 1. Ubicación y número de animales de los establos evaluados

\begin{tabular}{clcc}
\hline Establo & Ubicación & $\mathrm{N}^{\circ}$ de animales & Nivel tecnológico $^{1}$ \\
\hline 1 & Jauja & 3 & $\mathrm{~B}$ \\
2 & Jauja & 4 & $\mathrm{~B}$ \\
3 & Huancayo & 4 & $\mathrm{~A}$ \\
4 & Jauja & 4 & $\mathrm{~A}$ \\
5 & Jauja & 21 & $\mathrm{~A}$ \\
6 & Concepción & 4 & $\mathrm{~A}$ \\
\hline
\end{tabular}

${ }^{1} \mathrm{~A}=$ Alto, $\mathrm{B}=$ Bajo

Se determinó la concentración de progesterona en las muestras de leche por el método de radioinmunoensayo, siguiendo el protocolo disponible en el laboratorio y que fuera validado en trabajos previos (Evaristo y Echevarría, 1999; López, 1987).

Para los fines interpretativos, se consideró que la primera ovulación ocurrió cuando las muestras presentaron niveles de $\geq 3.18$ $\mathrm{nmol} / \mathrm{L}$ progesterona, seguido de al menos una muestra con niveles similares; el ciclo estrual se inició cuando los niveles de progesterona fueron $<1 \mathrm{nmol} / \mathrm{L}$ por un periodo de 3-6 días, seguida de niveles de $\geq 3.18 \mathrm{nmol} / \mathrm{L}$ por un periodo de 16-22 días; y el anestro ocurrió cuando se registraron niveles de progesterona de $\leq 1 \mathrm{nmol} / \mathrm{L}$ en más de tres muestras seguidas.

Se registró la producción láctea en forma semanal y adicionalmente en el día 30, 45,60 y 90 postparto.

\section{Análisis de datos}

Se utilizó el análisis de varianza y de regresión múltiple, considerando como variables dependientes el intervalo parto-primera ovulación (IPPO), intervalo parto-primer servicio (IPPS), e intervalo parto-concepción (IPC); y como variables independientes el número de partos (primíparas y multíparas), raza (Holstein y Brown Swiss), producción de leche (día 15, 30, 60 y 90, y producción acumulada), establo (1-6) y nivel tecnológico (alto y bajo). Los resultados se expresan como promedio de cuadrados mínimos y error estándar.

\section{Resultados}

El Cuadro 2 muestra los resultados del IPPO, IPPS e IPC. EL IPPO no se afectó por las variables en estudio. El IPPS fue afectado por el nivel tecnológico (A: $101.6 \pm 11.3$ y B: $187.9 \pm 23.0$ días, $\mathrm{p}<0.05$ ), mas no así por el IPPO, la raza, el número de parto, o la producción de leche. El IPC estuvo influenciado por el IPPS ( $\mathrm{p}<0.05)$, mas no así por la raza, número de partos, producción de leche o nivel tecnológico. El número de servicios por concepción fue de 1.8.

La producción de leche acumulada por vaca a los 30 días de lactancia fue de 501.9 \pm 25.6 y de $370.7 \pm 51.3 \mathrm{~L}$ para los niveles tecnológicos A y B, respectivamente $(\mathrm{p}<0.05)$. El promedio de producción de leche por vaca en ordeño entre los 15 y 90 días postparto descendió en forma gradual en el nivel tecnológico $\mathrm{A}$, en tanto que se mantuvo constante en el nivel B (Cuadro 3). 
Cuadro 2. Parámetros reproductivos de 6 establos lecheros del valle del Mantaro durante la época lluviosa (1999)

\begin{tabular}{|c|c|c|}
\hline Parámetro & $\mathrm{N}^{\circ}$ de animales & $\mathrm{CM} \pm$ ee (días) \\
\hline $\begin{array}{l}\text { IPPO (Intervalo entre el parto y la primera } \\
\text { ovulación) }\end{array}$ & 13 & $41.2 \pm 20.2$ \\
\hline $\begin{array}{l}\text { IPPS (Intervalo entre el parto y el primer } \\
\text { servicio) }\end{array}$ & 36 & $118.4 \pm 69.2$ \\
\hline $\begin{array}{l}\text { IPC Intervalo entre el parto y la } \\
\text { concepción) }\end{array}$ & 36 & $171.3 \pm 105.5$ \\
\hline
\end{tabular}

Cuadro 3. Producción de leche por vaca/día (litros) en los niveles tecnológicos alto (A) y bajo (B) (1999)

\begin{tabular}{ccccc}
\hline \multirow{2}{*}{ Nivel } & \multicolumn{5}{c}{ Días de lactancia } \\
\cline { 2 - 5 } & 30 & 45 & 60 & 90 \\
\hline A & 17.0 & 16.6 & 14.7 & 13.9 \\
B & 12.2 & 12.3 & 13.1 & 13.2 \\
\hline
\end{tabular}

\section{Discusión}

El promedio del parto a la primera ovulación debe ser de 20 días en condiciones de ganaderías lecheras (Canfield y Butler, 1991; Dick, 1998). El largo periodo de inactividad ovárica después del parto es una de las principales limitantes de la eficiencia reproductiva en vacunos. La duración del anestro postparto está influenciado entre otros factores, por la nutrición, edad y lactación. No obstante, en el presente estudio, el intervalo partoprimera ovulación fue dentro de lo esperado para las condiciones de vacas lecheras de la costa peruana (Evaristo y Echevarría, 1999; Díaz, 1992) y del Uruguay (MagañaMonforte y Delgado, 1998). Por otro lado, no se observó un efecto de la lactación, número de parto, raza, nivel tecnológico, ni del establo sobre el reinicio de la actividad ovárica.
Es posible que la abundancia de pastos en el periodo de lluvias haya garantizado un mejor nivel de nutrición en las vacas en lactación, ya que en otros estudios realizados en época seca (J. Segura, 2001, datos no publicados) se encontró que el reinicio de la actividad ovárica fue a los $87.3 \pm 31.2$ días.

Es importante resaltar que en el presente estudio, la máxima producción de leche entre los primeros 30 y 45 días de lactación fue de 26.5 litros. Bojórquez (1989) menciona que si las vacas bajo las condiciones del presente estudio tienen disponibilidad de materia seca en niveles de $3 \%$ de su peso corporal, podrían cubrir los requerimientos de producción de hasta 20 litros por día, sin la necesidad de recibir suplementos concentrados. Esto indica que estaría ocurriendo un déficit energético temporal que estaría siendo compensado con las reservas corporales. 
Según Villa-Godoy et al. (1988), la mayor variación en el balance energético durante la lactación temprana está más asociada con ingesta de energía que con producción láctea, por lo que aun las vacas de baja producción láctea pueden encontrarse en balance energético negativo.

La recomendación tradicional es inseminar las vacas en el primer celo detectado a partir de los 50-60 días después del parto. En condiciones de pastoreo (Magaña-Monforte y Delgado, 1998) y bajo estabulación en la costa peruana (Evaristo y Echevarría, 1999) se reportan intervalos entre 80 y 100 días entre el parto y el primer servicio. En el presente estudio, el nivel tecnológico fue determinante para el intervalo parto-primer servicio, y donde el nivel tecnológico alto mostró un comportamiento similar a lo reportado por los autores antes mencionados; en tanto que el nivel tecnológico B mostró una respuesta pobre (187 días en promedio). Estas diferencias pueden ser debido al tipo de manejo y a la detección de celo. A menudo el ganadero no le presta la atención debida a la vaca en estro, ya sea por el número limitado de observaciones, por el tiempo de observación, porque el periodo de estro es muy breve o se produce por la noche, o porque los métodos de detección no son los más adecuados. Este resultado podría además deberse a que los animales que paren en época lluviosa, a pesar que el reinicio de la actividad ovárica es similar a vacas de la costa, estarían sometidos a un manejo inadecuado con respecto a detección de estro. Las condiciones de precipitación pluvial en esta época serían también un factor que limitaría la observación de celos en las vacas, ya que el personal encargado de esta labor, sobre todo al atardecer y por las noches, se protege de la lluvia y no va al campo a detectar celo.

Otros estudios, como los realizados por Morales et al. (1990), señalan que las vaquillas presentan más ovulaciones silentes y celos anovulatorios en la época lluviosa que en la época seca (32.7 y $13.1 \%$ vs. 27.4 y
$11.1 \%$, respectivamente). Asimismo, señala que del 15 al $25 \%$ de las ovulaciones se producen sin manifestaciones conductuales típicas de celo, determinando que la detección de celo sea un problema de manejo.

El intervalo entre el parto y la concepción encontrado en el presente estudio (171 \pm 105 días) tuvo una gran variabilidad y se encontró por encima del intervalo parto-concepción considerado como apropiado para este tipo de animales. Es así que se han obtenido intervalos de $131 \pm 77$ días y 154 días en México (Ramírez y Segura, 1992; MagañaMonforte y Delgado, 1998, respectivamente), $11 \pm 55$ días en Ecuador (Jarrín et al., 1990), y de $113 \pm 61$ días en la costa peruana (Evaristo y Echevarría, 1999).

El IPC, también llamado días abiertos, es un índice valioso que refleja la eficiencia en la detección del estro y la fecundidad de la hembra. En este estudio el IPC es largo en comparación con los datos de la región costeña y de animales de otras latitudes, principalmente debido a factores tales como una deficiente detección de celos.

Otro aspecto sería que, si bien las vacas tienen un IPPO más corto en la época de lluvias, debido principalmente a la abundancia de pastos, los animales no alcanzarían niveles de nutrición adecuados a partir de mayo, afectándose de esta manera las manifestaciones estruales e incluso las vacas podrían entrar en periodos de anestro. En esta situación estarían expuestas las vacas que paren en febrero y marzo (Arthur, 1991).

\section{Conclusiones}

El intervalo observado entre el parto y la primera ovulación $(41.2 \pm 20.2$ días $)$ estuvo dentro de los rangos esperados para bovinos de producción de leche criados bajo las condiciones del presente estudio. Sin embargo, los intervalos entre el parto al primer servicio $(118.4 \pm 69.2)$ y a la concepción (171.3 
\pm 105.5 días) fueron muy prolongados, debido posiblemente a problemas en la detección del celo y limitantes nutricionales. El nivel tecnológico de los establos fue la única variable de importancia que afectó el intervalo partoprimer servicio.

\section{Literatura Citada}

1. Arthur, G. 1991. Reproducción y obstetricia en veterinaria. $1^{a}$ ed. $p$ 125128. Ed. Interamericana. España.

2. Bojórquez, C. 1989. Alimentación del ganado lechero en base a pasturas cultivadas (Sierra). Asociación Peruana de Producción Animal. APPA. Lima.

3. Canfield, R.; W. Butler. 1991. Energy balance, first ovulation and the effects of naloxone on LH secretion in early post partum dairy cows. J. Anim. Sci. 69: 740746.

4. Díaz, V. 1992. Actividad ovárica postparto en vacas lecheras de crianza intensiva. Tesis de Médico Veterinario, Facultad de Medicina Veterinaria, Univ. Nacional Mayor de San Marcos. 45 p.

5. Dick, A. 1998. Manejo reproductivo y fertilidad en rodeos lecheros. XVIII Curso Internacional de Producción Lechera. Tomo III. INTA-Rafaela. Argentina.

6. Evaristo, R.; L. Echevarría. 1999. Factores que afectan el intervalo parto primer servicio en vacas lecheras de crianza intensiva. Rev. Inv. Vet., Perú 10: 22-26.

7. Friend, T. 1991. Behavioral aspects of stress. J. Dairy Sci. 74: 292-303.
8. Hafez, E. 1987. Reproducción e inseminación artificial en animales. $5^{\mathrm{a}}$ ed. Interamericana. México. 678 p.

9. Jarrín, J.; P. Villalba; E. Guerrón; E. Zurita. 1990. Estudio de la actividad ovárica post-parto de ganado lechero del Ecuador bajo diferentes sistemas de alimentación. En: Livestock Reproduction in Latin America. p 43-54. IAEA. Viena.

10.López, T. 1987. Ciclos estruales irregulares en ganado bovino bajo condiciones de trópico húmedo. Tesis de Médico Veterinario Facultad de Medicina Veterinaria, Univ. Nacional Mayor de San Marcos. 79 p.

11. Magaña-Monforte, J.; R. Delgado. 1998. Algunas observaciones sobre el comportamiento reproductivo de vacas pardo suizo en el trópico sub-húmedo de México. Facultad de Medicina Veterinaria y Zootecnia. Universidad Autónoma de Yucatán, Mérida, México.

12. Morales, J.; R. Pedroso; R. Solano; R. de Armas. 1990. Effects of a sub-tropical climate on the fertility of dairy cattle in Cuba. En: Livestock Reproduction in Latin America. p 29-42. IAEA. Viena.

13. Ramírez, R.; J. Segura. 1992. Comportamiento reproductivo de un hato de vacas Holstein en el noreste de México. Livest. Res. Rural Dev. 4(2): 7 p. Disponible en: www.cipav.org.co/lrrd/

14. Villa-Godoy, A.; T. Hughes; R. Emery; L. Chapin; R. Fogwell. 1988. Association between energy balance and luteal function in lactating dairy cows. J. Dairy Sci. 68: 1980-1987. 